Article

\title{
Antidepressant Potential of Lotus corniculatus L. subsp. corniculatus: An Ethnobotany Based Approach
}

\author{
Fatma Tuğçe Gürağaç Dereli ${ }^{1}$, Haroon Khan ${ }^{2}$, Eduardo Sobarzo-Sánchez ${ }^{3,4, * *(1)}$ and \\ Esra Küpeli Akkol 1,*iD \\ 1 Department of Pharmacognosy, Faculty of Pharmacy, Gazi University, 06330 Etiler, Ankara, Turkey; \\ ecztugceguragac@gmail.com \\ 2 Department of Pharmacy, Abdul Wali Khan University, Mardan 23200, Pakistan; \\ haroonkhan@awkum.edu.pk \\ 3 Instituto de Investigación e Innovación en Salud, Facultad de Ciencias de la Salud, Universidad Central de \\ Chile, 8330507 Santiago, Chile \\ 4 Department of Organic Chemistry, Faculty of Pharmacy, University of Santiago de Compostela, \\ 15782 Santiago de Compostela, Spain \\ * Correspondence: eduardo.sobarzo@ucentral.cl (E.S.-S.); esrak@gazi.edu.tr (E.K.A.); \\ Tel.: +90-569-53972-783 (E.S.-S.); +90-312-2023-185 (E.K.A.)
}

Academic Editor: Patrizia Russo

Received: 13 February 2020; Accepted: 10 March 2020; Published: 12 March 2020

\begin{abstract}
As a Turkish traditional medicinal plant, aerial parts of Lotus corniculatus L. subsp. corniculatus (Fabaceae) are used as a painkiller, antihemoroidal, diuretic and sedative. In this study, the antidepressant potential of the plant has been attempted to clarify. Extracts with water, $n$-Hexane, ethyl acetate, and methanol were prepared respectively from the aerial parts. Antidepressant activity of the extracts were researched by using three different in vivo test models namely a tail suspension test, antagonism of tetrabenazine-induced hypothermia, ptosis, and suppression of locomotor activity and forced swimming test on male BALB/c mice and in vitro monoamine oxidase (MAO)-A and B inhibition assays. The results were evaluated through comparing with control and reference groups, and then active compounds of the active extract have been determined. Bioassay-guided fractionation of active fraction led to the isolation of three compounds and structures of the compounds were elucidated by spectroscopic methods. The data of this study demonstrate that the MeOH extract of the aerial parts of the plant showed remarkable in vivo antidepressant effect and the isolated compounds medicarpin-3-O-glucoside, gossypetin-3-O-glucoside and naringenin-7-O-glucoside (prunin) from the active sub-fractions could be responsible for the activity. Further mechanistic and toxicity studies are planned to develop new antidepressant-acting drugs.
\end{abstract}

Keywords: antidepressant; Lotus corniculatus; Fabaceae; forced swimming test; monoamine oxidase; tail suspension test; tetrabenazine

\section{Introduction}

Depression is a common but serious mood disorder and its etiology has not yet been elucidated. The studies to date have shown that the onset of this disease may be associated with several genetic, biological and psychosocial risk factors [1]. The symptoms of depression can vary from mild to severe and include emotional, cognitive, behavioral and physical changes and all of these can cause disruptions in normal daily activities of individuals [2,3]. In addition to psychosocial problems, it can lead to some other additional diseases such as asthma, diabetes, obesity and cancer [4]. The World Health Organization estimate that over 300 million people suffer from depression and about 800,000 people die each year in suicide cases due to it [5]. The treatment of this serious public health problem is very important because of its financial and moral damages. 
The three most known treatment options for depression are psychotherapy, antidepressant medication and brain stimulation therapies. However, the most preferred treatment is a combination of the medication and cognitive behavioral therapy. There are many different types of antidepressants that can help reduce the symptoms of depression including monoamine oxidase (MAO) inhibitors, tricyclic antidepressants, specific serotonin-noradrenaline reuptake inhibitors and atypical antidepressants [6]. Due to the common serious side effects of available depression medicines such as weight gain, insomnia and sexual dysfunction, researchers continue to search for new alternative drug molecules in the treatment [7]. The ethnobotanical-based approach is particularly important for diseases such as depression that have not achieved a satisfactory therapeutic level. In such studies, antidepressant activities of various phytochemicals have been tried to be elucidate in the light of ethnobotanical information [8].

In this current study, the antidepressant activity of Lotus corniculatus L. subsp. corniculatus from Fabaceae family has been attempted to clarify. For aught we know, no report about the antidepressant potential of the plant is available to date. As a Turkish traditional medicinal plant, aerial parts of the plant are used as painkiller, antihemorrhoidal, diuretic and sedative [9]. The bioassay-guided fractionation process was preferred to investigation of the main active chemical compounds of the plant.

\section{Results}

\subsection{Biological Activity Studies}

In this study, in vivo antidepressant activity of a Turkish medicinal plant, L. corniculatus subsp. corniculatus was investigated by using three different in vivo test models namely forced swimming test, tail suspension test and antagonism of tetrabenazine-induced ptosis, hypothermia and suppression of locomotor activity and in vitro MAO inhibition assay.

Firstly, the aqueous extract was prepared according to traditional usage. In vivo tests results for aqueous extract were summarized in Table 1. As shown, the aqueous extract did not show any remarkable antidepressant activity. Due to this extract did not show any remarkable antidepressant activity, the activity of three different extracts was obtained by successive extraction with n-hexane, EtOAc and $\mathrm{MeOH}$ were evaluated.

Table 1. Effects of the aqueous extracts prepared from the aerial parts of Lotus corniculatus L. subsp. corniculatus in the antidepressant activity tests.

\begin{tabular}{|c|c|c|c|c|}
\hline \multicolumn{5}{|c|}{ Forced Swimming Test } \\
\hline Material & Dose (mg/kg. p.o.) & Duration of Immobility (s) (Mean \pm S.E.M.) & & Variation $(\%)$ \\
\hline Control & - & $205.13 \pm 22.54$ & & - \\
\hline Aqueous extract & 100 & $204.66 \pm 22.49$ & & -0.23 \\
\hline Imipramine $\mathrm{HCl}$ & 50 & $85.41 \pm 7.64 * * *$ & & -58.36 \\
\hline \multicolumn{5}{|c|}{ Tail Suspension Test } \\
\hline Imipramine $\mathrm{HCl}$ & 50 & $71.26 \pm 6.91 * * *$ & & -66.91 \\
\hline \multicolumn{5}{|c|}{ Antagonism of Tetrabenazine-Induced Ptosis, Hypothermia and Suppression of Locomotor Activity } \\
\hline Material & Dose (mg/kg) & Ptosis Mean Score (Mean \pm S.E.M.) & $\begin{array}{l}\text { Locomotor } \\
\text { Activity }(\%)\end{array}$ & $\begin{array}{c}\text { Mean Decrease in Rectal Temperature } \\
\left({ }^{\circ} \mathrm{C}\right)(\text { Mean } \pm \text { S.E.M. })\end{array}$ \\
\hline Control & - & $3.83 \pm 1.27$ & 0.00 & $5.12 \pm 0.43$ \\
\hline
\end{tabular}

The $\mathrm{MeOH}$ extract reduced the immobility period by $33.40 \%(p<0.05)$ compared to the control group and this result was found to be statistically significant (Table 2).

As shown in Table 3, similar results were received for TST. The MeOH extract shortened the immobility time significantly with the value of $38.11 \%(p<0.05)$ compared to the control group and this reduction was found to be statistically significant. 
Table 2. Effects of the extracts and fractions prepared with organic solvents from Lotus corniculatus L. subsp. corniculatus in the forced swimming test.

\begin{tabular}{|c|c|c|c|}
\hline \multicolumn{4}{|c|}{ Effects of the Extracts } \\
\hline Material & Dose $(\mathrm{mg} / \mathrm{kg})$ & Duration of Immobility (s) (Mean \pm S.E.M.) & Variation $(\%)$ \\
\hline Control & - & $210.17 \pm 25.59$ & - \\
\hline$n$-Hexane extract & \multirow{3}{*}{100} & $142.31 \pm 20.86$ & -32.29 \\
\hline EtOAc extract & & $165.40 \pm 25.02$ & -21.30 \\
\hline $\mathrm{MeOH}$ extract & & $139.97 \pm 19.03 * *$ & -33.40 \\
\hline \multirow{2}{*}{ Imipramine $\mathrm{HCl}$} & 30 & $115.76 \pm 10.48 * *$ & -44.92 \\
\hline & 50 & $91.27 \pm 8.63 * * *$ & -56.57 \\
\hline \multicolumn{4}{|c|}{ Effects of the Fractions Obtained from Active MeOH Extract } \\
\hline Control & - & $205.21 \pm 22.31$ & - \\
\hline Fr. $(1-12)$ & \multirow{4}{*}{100} & $129.42 \pm 13.09$ & -36.93 \\
\hline Fr. $(13-20)$ & & $115.22 \pm 11.03 * *$ & -43.85 \\
\hline Fr. (21-35) & & $140.24 \pm 18.03$ & -31.66 \\
\hline Fr. $(36-42)$ & & $150.46 \pm 19.02$ & -26.68 \\
\hline \multirow{2}{*}{ Imipramine $\mathrm{HCl}$} & 30 & $106.11 \pm 9.85^{* *}$ & -48.29 \\
\hline & 50 & $85.47 \pm 7.40^{* * *}$ & -58.35 \\
\hline
\end{tabular}

Table 3. Effects of the extracts and fractions prepared with organic solvents from Lotus corniculatus L. subsp. corniculatus in the tail suspension test.

\begin{tabular}{|c|c|c|c|}
\hline \multicolumn{4}{|c|}{ Effects of the Extracts } \\
\hline Material & Dose (mg/kg) & Duration of immobility (s) (Mean \pm S.E.M.) & Variation $(\%)$ \\
\hline Control & - & $203.50 \pm 22.13$ & - \\
\hline$n$-Hexane extract & & $131.99 \pm 17.03$ & -35.14 \\
\hline EtOAc extract & 100 & $140.38 \pm 19.87$ & -31.02 \\
\hline $\mathrm{MeOH}$ extract & & $125.94 \pm 16.57^{* *}$ & -38.11 \\
\hline Iminmmine $\mathrm{HCl}$ & 30 & $88.11 \pm 8.01 * * *$ & -56.70 \\
\hline Imipramine $\mathrm{HCl}$ & 50 & $75.37 \pm 7.32 * * *$ & -62.96 \\
\hline \multicolumn{4}{|c|}{ Effects of the Fractions Obtained from Active MeOH Extract } \\
\hline Material & Dose (mg/kg. p.o.) & Duration of immobility (s) (Mean \pm S.E.M.) & Variation (\%) \\
\hline Control & - & $210.11 \pm 25.05$ & - \\
\hline Fr. $(1-12)$ & & $158.27 \pm 19.29$ & -24.67 \\
\hline Fr. (13-20) & \multirow{3}{*}{100} & $115.41 \pm 14.17^{\text {** }}$ & -45.07 \\
\hline Fr. $(21-35)$ & & $145.36 \pm 18.46$ & -30.82 \\
\hline Fr. $(36-42)$ & & $131.12 \pm 19.73$ & -37.59 \\
\hline \multirow{2}{*}{ Imipramine $\mathrm{HCl}$} & 30 & $90.02 \pm 9.71 * *$ & -57.16 \\
\hline & 50 & $81.46 \pm 6.42 * * *$ & -61.23 \\
\hline
\end{tabular}

Similar results were obtained in the antagonism of ptosis and hypothermia induced by tetrabenazine test, as indicated in Table 4. The $\mathrm{MeOH}$ extract increased the locomotor activity by $33.3 \%$, reduced the ptosis score to 1.75 and changed rectal temperature with a decrease of $1.51{ }^{\circ} \mathrm{C}$.

Table 4. Effects of the extracts and fractions prepared with organic solvents from Lotus corniculatus L. subsp. corniculatus in the antagonism of tetrabenazine-induced ptosis, hypothermia and suppression of locomotor activity tests.

\begin{tabular}{|c|c|c|c|c|}
\hline \multicolumn{5}{|c|}{ Effects of the Extracts } \\
\hline Material & $\operatorname{Dose}(\mathrm{mg} / \mathrm{kg})$ & Ptosis mean score(Mean \pm S.E.M.) & $\begin{array}{r}\text { Locomotor } \\
\text { Activity (\%) }\end{array}$ & $\begin{array}{c}\text { Mean Decrease in Rectal } \\
\text { Temperature }\left({ }^{\circ} \mathrm{C} ; \text { Mean } \pm \text { S.E.M. }\right)\end{array}$ \\
\hline Control & - & $3.83 \pm 1.29$ & 0.00 & $5.01 \pm 0.43$ \\
\hline$n$-Hexane extract & & $2.25 \pm 0.86$ & 16.7 & $1.46 \pm 0.11$ \\
\hline EtOAc extract & 100 & $2.50 \pm 0.96$ & 33.3 & $3.28 \pm 0.27$ \\
\hline $\mathrm{MeOH}$ extract & & $1.75 \pm 0.52 * *$ & $66.7 * *$ & $1.51 \pm 0.13 * *$ \\
\hline Fluoxetine $\mathrm{HCl}$ & 25 & $0.00 \pm 0.00 * * *$ & $100.00 * * *$ & $0.24 \pm 0.02 * * *$ \\
\hline \multicolumn{5}{|c|}{ Effects of the Fractions Obtained from Active MeOH Extract } \\
\hline Control & - & $3.82 \pm 1.23$ & 0.00 & $5.23 \pm 0.47$ \\
\hline Fr. (1-12) & & $2.23 \pm 0.82$ & 16.7 & $3.28 \pm 0.27$ \\
\hline Fr. (13-20) & & $0.15 \pm 0.03 * *$ & $66.7 * *$ & $0.58 \pm 0.07 * *$ \\
\hline Fr. $(21-35)$ & 100 & $2.27 \pm 0.83$ & 16.7 & $3.82 \pm 0.33$ \\
\hline Fr. $(36-42)$ & & $2.11 \pm 0.76$ & 33.3 & $2.68 \pm 0.18$ \\
\hline Fluoxetine $\mathrm{HCl}$ & 25 & $0.00 \pm 0.00 * * *$ & $100.00 * * *$ & $0.27 \pm 0.02 * * *$ \\
\hline
\end{tabular}

${ }^{* *}: p<0,01 ;{ }^{* * *}: p<0,001$ (S.E.M.: Standard Error of the Mean). 
However, the extracts inhibited MAO-A and MAO-B enzymes with the high $\mathrm{IC}_{50}$ values in the MAO inhibition assay (Table 5), all of the received results from in vivo studies led to the isolation studies on active $\mathrm{MeOH}$ extract.

Table 5. Effect of extracts and fractions obtained from Lotus corniculatus L. subsp. corniculatus on the MAO inhibition assay.

\begin{tabular}{lll}
\hline Material & \multicolumn{2}{c}{ IC $_{\mathbf{5 0}}(\mathbf{m g} / \mathbf{m L}) \pm$ S.D. } \\
\hline Control & MAO-A & MAO-B \\
Aqueous extract & $0.182 \pm 0.022$ & $0.115 \pm 0.046$ \\
n-Hexane extract & $2.273 \pm 0.149$ & $2.371 \pm 0.058$ \\
EtOAc extract & $4.154 \pm 0.927$ & $1.196 \pm 0.136$ \\
MeOH extract & $9.315 \pm 2.719$ & $5.182 \pm 1.049$ \\
Fr. (1-12) & $1.408 \pm 0.612$ & $7.109 \pm 1.172$ \\
Fr. (13-20) & $8.923 \pm 2.041$ & $3.524 \pm 1.281$ \\
Fr. (21-35) & $3.287 \pm 1.925$ & $9.305 \pm 2.972$ \\
Fr. (36-42) & $1.054 \pm 0.258$ & $1.471 \pm 0.228$ \\
& \multicolumn{2}{c}{ IC $_{50}$ (M) } \\
\hline Caffeine & $0.004 \pm 0.001$ & $0.003 \pm 0.001$ \\
\hline
\end{tabular}

Reverse phase C18 (RP-18) column chromatography was performed on this extract to elute pure compounds responsible from the activity. The obtained fractions were characterized by thin-layer chromatograms and grouped into four categories (Fractions 1-42). All of the fractions inhibited MAO-A and MAO-B enzymes with the high $\mathrm{IC}_{50}$ values in MAO inhibition assay and of these fractions, only the Fr. (13-20) fraction showed the most potent activity in in vivo assays (Tables 2-5). Therefore, the Fr. (13-20) fraction was fractionated to the three subfractions by Sephadex LH-20 with MeOH and three compounds were isolated.

\subsection{Structure of Isolated Compounds}

The structures of the isolates were elucidated to be medicarpin 3-O-glucoside, gossypetin-3-O-glucoside and naringenin-7-O-glucoside (Figure 1).<smiles></smiles>
medicarpin-3-O-glucoside gossypetin-3-O-glucoside

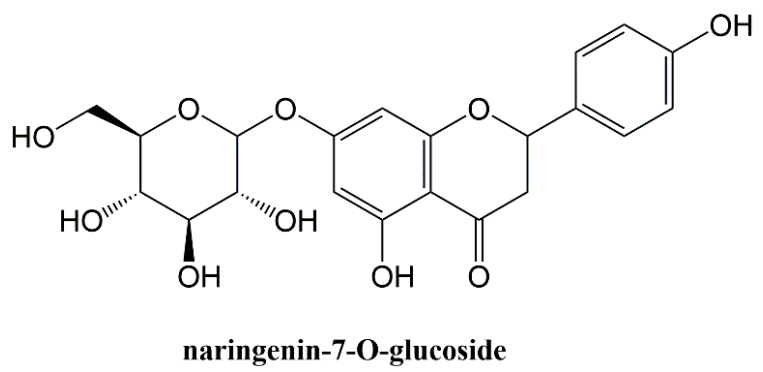

Figure 1. Chemical structures of isolated compounds. 


\section{Discussion}

Natural resources have been used for treatment purposes for ages and plants are the most favorite among them [10]. In this study, in vivo antidepressant activity of a Turkish medicinal plant, L. corniculatus subsp. corniculatus was investigated by using three different in vivo test models namely forced swimming test, tail suspension test, and antagonism of tetrabenazine-induced ptosis, hypothermia and suppression of locomotor activity and an in vitro MAO inhibition assay.

Phytochemical investigation studies on $L$. corniculatus reported the isolation of several flavonoid compounds and glycosides such as quercetin, naringenin, hyperoside, quercetin- $O$-deoxyhexoside- $O$-hexoside,quercetin-3-O-rhamnoside-7-O-glucoside,quercetin-3, 7dirhamnoside,isoquercitrin,quercetin-O-pentoside,quercitrin,kaempferol-3-O-[xylosyl-(1 $\rightarrow 2)$ galactoside]-7-O-rhamnoside,kaempferol-7-O-glucoside, afzelin,kaempferol-O-deoxyhexosylhexosideO-deoxyhexoside, kaempferol-3-O-rhamnoside-7-O-glucoside, gossypetin, gossypetin-3-O-galactoside, gossytrin, medicarpin, medicarpin-3-O- $\beta$-D-glucopyranoside; saponoids such as soyasaponin I, dehydrosoyasaponin I, pharbitoside A; benzoic acid and cinnamic acid derivatives include p-coumaric acid, caffeic acid and chlorogenic acid so far [11-14]. However, to the best of our knowledge, there is no study about the chemical composition and also antidepressant activity of L. corniculatus subsp. corniculatus. There is at present only one bioactivity study in the literature and this one is related to the cytotoxicity potential and antioxidant effect of the plant [15]. In this sense, this study is the first in determining the activity against depression and also the chemical profile of the plant.

Plenty of studies have been designed to assess the antidepressant-like activity of flavonoids so far and activity mechanism of this type of compounds is thought to be gene regulation for reversing of monoamine neurotransmitter attenuation or neurotransmitter receptor expression [16].

Medicarpin is a pterocarpan (a derivative of isoflavonoids) and pterocarpan derivative compounds have been mainly found in species belonging to the Fabaceae family. Several plants that contain pterocarpans have been used in traditional medicine of many diverse cultures as an oral antidote against the venoms of snakes and spiders [17] and previous studies revealed that pterocarpan containing plants have antifungal, antibacterial, antitumoral and anti-inflammatory activities [18-20]. So far, potential antidepressant effects of some isoflavones have been evaluated and the involvement of noradrenergic, serotonergic and dopaminergic mechanisms have been thought to be responsible for the activity [16]. However, medicarpin derivative compounds have never been studied for their antidepressant effects [21,22].

Gossypetin is a hexahydroxylated flavonoid and named in chemistry as $3,5,7,8,3^{\prime}, 4^{\prime}$ hexahydroxy flavone. There are several studies that have shown that this compound has diuretic, antioxidant, antimicrobial, antimutagenic, antiatherosclerotic, cytoprotective, anxiolytic and antidepressant effects [23-25]. In a study that was designed to investigate the antidepressant and antianxiety potentials of Hibiscus sabdariffa Linn. (Malvaceae) calyces, which have been used traditionally as a sedative and for treating other nervous disorders, gossypetin has been shown to exhibit significant antidepressant and antianxiety activity at the dose of 20 and $5 \mathrm{mg} / \mathrm{kg}$ po, respectively [26] Gossypetin-8-O- $\beta$-D-glucuronide which isolated from Abelmoschus manihot (L.) Medic. has been showed an obvious antidepressant activity via up-regulation of BDNF expression [27].

Naringenin is a naturally occurring flavanone known to have anticancer, antimutagenic, anti-inflammatory, antioxidant, antiproliferative, hepatoprotective and antiatherogenic activities [28-31]. Naringenin was also studied for its antidepressant activity and it was observed that this compound possessed powerful anti-depressant like activity via the central serotonergic and noradrenergic systems [32,33].

Currently commercially available drugs for the treatment of depression are associated with various adverse effects and have many other disadvantages such as relatively low response and problematic interactions [34]. For these reasons, searches for novel pharmacotherapeutics from medicinal plants are still ongoing. 


\section{Materials and Methods}

\subsection{Plant Material}

Fresh aerial parts of L. corniculatus subsp. corniculatus were collected on the date of 18.05.2018 from the roadside of Isparta-Konya highway in Turkey and authenticated by Prof. Dr. Hasan ÖZÇELIK from Süleyman Demirel University, Department of Biology, Faculty of Science and Art, Isparta. A voucher specimen with the code GUEF3467 was deposited in the Herbarium of the Faculty of Pharmacy, Gazi University, Ankara, Turkey.

\subsection{Extraction, Fractionation and Isolation Process}

Firstly, considering the traditional usage of the plant, milled dry aerial parts were extracted with distilled water at room temperature. As the aqueous extract did not show any remarkable activity in used experimental models of depression in mice, n-hexane, ethyl acetate (EtOAc) and methanol $(\mathrm{MeOH})$ extracts were prepared sequentially through maceration method. The percentage yield of the EtOAc extract $(12.4 \%)$ was higher than $n$-hexane $(4.6 \%)$ and methanolic $(11.7 \%)$ extracts. Since the $\mathrm{MeOH}$ extract of the plant material was found active in experiments, it was decided to fractionate.

\subsubsection{Fractionation of $\mathrm{MeOH}$ Extract}

The $\mathrm{MeOH}$ extract (16 g) was subjected to RP-18 column vacuum liquid chromatography ( $\mathrm{H}_{2} \mathrm{O}$ (2 L), $\mathrm{H}_{2} \mathrm{O}: \mathrm{MeOH}$ (90:10, 1 L), $\mathrm{H}_{2} \mathrm{O}: \mathrm{MeOH}(80: 20,1 \mathrm{~L}), \mathrm{H}_{2} \mathrm{O}: \mathrm{MeOH}$ (70:30, 2 L), $\mathrm{H}_{2} \mathrm{O}: \mathrm{MeOH}$ (60:40, 2 L), $\mathrm{H}_{2} \mathrm{O}: \mathrm{MeOH}\left(50: 50,2\right.$ L), $\mathrm{H}_{2} \mathrm{O}: \mathrm{MeOH}(40: 60,2 \mathrm{~L}), \mathrm{H}_{2} \mathrm{O}: \mathrm{MeOH}$ (30:70, 2 L), $\mathrm{H}_{2} \mathrm{O}: \mathrm{MeOH}$ (20:80, 2 L), $\mathrm{H}_{2} \mathrm{O}: \mathrm{MeOH}(10: 90,1 \mathrm{~L}), \mathrm{MeOH}(1 \mathrm{~L})$, acetone $(1 \mathrm{~L})$ ) to obtain 42 fractions, which were combined as follows Fractions 1-42 after thin-layer chromatography (TLC) control (Mobile phase: EtOAc: $\mathrm{CHCl}_{3}: \mathrm{MeOH}: \mathrm{H}_{2} \mathrm{O}$ (6:4:4:1)). Since the Fr. (13-20) fraction were displayed the potent antidepressant activity, this fraction applied to Sephadex LH-20 (25-100 $\mu \mathrm{m}$, Sigma Chem. Co.) column using $\mathrm{MeOH}$ to obtain pure compounds.

\subsubsection{Determination of the Structure of Compounds}

The structural determination of the compounds was achieved by mass spectroscopy (MS; Agilent G6550A Q-TOF mass spectrometer and Waters LCT Premier XE UPLC/MS-TOF spectrometer) and nuclear magnetic resonance $\left({ }^{1} \mathrm{H}\right.$ and ${ }^{13} \mathrm{C}$ NMR; Bruker Ascend spectrometer) techniques. Totally 3 compounds were isolated from active fraction and the isolates were identified medicarpin-3-O-glucoside (a pterocarpan glycoside), gossypetin-3-O-glucoside (a flavonol glycoside) and naringenin-7-O-glucoside (prunin; a flavanone glycoside) by comparing their spectroscopic data with related literatures [35-37].

\subsection{Biological Activity Tests}

\subsubsection{Animals}

The experiments were conducted on male BALB/c mice (25-30 g) and male Sprague-Dawley male rats (180-200 g), which were provided from Kobay Animals Laboratory (Ankara, Turkey) and kept in 12-h light/dark cycle for 3 days at room conditions with free access to laboratory food and water tap ad libitum. Six animals were used for each experimental group and all of the in vivo behavioral experiments were performed conferring to the international rules regarding the animal experiments and biodiversity rights (Kobay Ethical Council Project Number: 255).

\subsubsection{Preparation of Test Samples for Bioassay}

All of the extracts were suspended in sodium carboxymethyl cellulose solution ( $0.5 \% \mathrm{CMC})$ using an ultrasonic bath and test samples were administered to the test group animals by oral gavage at the dose of $100 \mathrm{mg} / \mathrm{kg}$. In the control group, animals received only $0.5 \% \mathrm{CMC}$ solution to eliminate the 
effect of carrier material on biological activity and determine truly the effectiveness of the test materials, Fluoxetine (25 mg/kg dose; Merck, Darmstadt, Germany) and imipramine (30 and $50 \mathrm{mg} / \mathrm{kg}$ doses; Merck, Darmstadt, Germany) in 0.5\% CMC were selected as reference drugs.

\subsubsection{Forced Swimming Test}

Forced swimming test (FST) was carried out according to the methodology described by Porsolt et al. (1977) with some modifications [38,39]. This test model is based on that the inactivity of mice reflects the behavioral despair seen in depressive people. One hour after administering the test materials, the mice were individually forced to swim in a 20-cm-high transparent glass cylinder containing 8-cm-deep water at $21-24^{\circ} \mathrm{C}$ and left there for $6 \mathrm{~min}$. The water in the vessel was changed after each trial. Each animal was used only once. The test was videotaped, and the total duration of immobility was measured during the last 4-min interval of the test. Immobility, climbing and swimming behaviors were recorded. The mice were considered immobile only when they made no additional attempts to escape except the movements needed to keep their heads above the water. Six mice were used for each test group.

\subsubsection{Tail Suspension Test}

Tail suspension test (TST) was performed as described by Steru et al. (1985) with minor modifications $[40,41]$. This test is based on the determination of the period of immobility of mice like FST. The mice, both acoustically and visually isolated, were hung $50 \mathrm{~cm}$ above the floor with the help of an adhesive tape placed approximately $1 \mathrm{~cm}$ from the tip of the tail one hour after administering the test samples orally. The test was videotaped, and the total duration of immobility time was chronometered for $6 \mathrm{~min}$ of the 10-min period. The mice were considered immobile only when they did not show any body movement, hung passively and stayed completely motionless for at least $1 \mathrm{~min}$. Six mice were used for each test group.

\subsubsection{Antagonism of Hypothermia and Ptosis Induced by Tetrabenazine}

The antagonism of tetrabenazine-induced hypothermia, ptosis and suppression of locomotor activity test was performed as described by Alpermann et al. [42]. This test is based on the observation of changes in the ptosis scores, rectal temperatures and durations of immobilization of mice. The mice with rectal temperatures of $36-38{ }^{\circ} \mathrm{C}$ were used in these experiments. One hour after oral administration of suitable materials for the animals in the control and experimental groups, tetrabenazine, which was dissolved in $0.1 \mathrm{M}$ aqueous tartaric acid solution and adjusted to $\mathrm{pH} 6$ with $10 \% \mathrm{NaOH}$ administered intraperitoneally at $32 \mathrm{mg} / \mathrm{kg}$. Thirty minutes after administration, the animals were placed one by one in the center of a $20 \mathrm{~cm}$ diameter disc and their locomotor activity percentages, ptosis scores and rectal temperature changes were determined. Mice walking to the edge of the disc and looking to the edge, rotating $180^{\circ}$ in place, or moving the head $90^{\circ}$ in one direction were not considered akinetic. The following formula was used to calculate the percentage of animals showing locomotor activity:

Locomotor activity $(\%)=($ Number of non-akinetic mice $\times 100) /$ Number of mice in group

The ptosis scoring was done according to the following scale:

0: Eyes open;

1: One quarter off;

2: Half closed;

3: Three quarters off;

4: Fully enclosed.

Sixty min after the administration of tetrabenazine, the rectal temperature of each mouse was measured again with a clinical digital thermometer (BIO-TK9882 Rodent Thermometer) to record the change. Six mice were used for each test group. 


\subsubsection{The Inhibitory Activity on the MAO A\&B}

The effects of prepared extracts and fractions obtained from $\mathrm{MeOH}$ extract on the activity of MAO-A and B enzymes were investigated in vitro in the brain and liver of the rats according to the methods reported by Hwang et al. (2003) and Küpeli Akkol et al. (2019) with some modification [43,44]. The anesthetized rats were lost blood with 3.13\% sodium citrated syringe from heart. The brain tissue was obtained from the decapitated brain, which was washed with $0.01 \mathrm{M}$ phosphate buffered saline (PBS, pH 7.0), and homogenate at $40^{\circ} \mathrm{C}$ for $1 \mathrm{~min}$ followed by added cold $0.25 \mathrm{M}$ sucrose by 9 parts of wet weight of tissue. Centrifuged at $700 \times g$ in $40{ }^{\circ} \mathrm{C}$ for $20 \mathrm{~min}$. Supernatant was centrifuged at $18,000 \times \mathrm{g}$ for $20 \mathrm{~min}$ immediately. Pellet was suspended in 5 parts of PBS, and used for crude enzyme preparation. Prepared crude MAO-A $(0.5 \mathrm{~mL})$ was added to test tubes with $1.0 \mathrm{~mL}$ of test materials. It was incubated in shaking incubator at $37.5^{\circ} \mathrm{C}$ for $15 \mathrm{~min}$. As a substrate, $0.5 \mathrm{~mL}$ of $1.0 \mathrm{mM}$ serotonin was added and incubated at $37.5^{\circ} \mathrm{C}$ for $90 \mathrm{~min}$. To terminate the enzyme action, test tubes were heated at $95^{\circ} \mathrm{C}$ water bath for $3 \mathrm{~min}$. and centrifuged at $700 \times g$ for $20 \mathrm{~min}$. immediately. Supernatants were poured in prepared Amberlite CG-50 (H+ form) column $(0.6 \mathrm{~cm} \times 4 \mathrm{~cm})$. After washed with distilled water thoroughly (over $40 \mathrm{~mL}$ ), eluted with $3 \mathrm{~mL}$ of $4 \mathrm{~N}$ acetic acid, elute was determined of absorbance at $277 \mathrm{~nm}$. Instead of samples, same volumes of distilled water were added in control. In the sample controls, the substrates were added on the time of activity termination instead of initiation of action. Each group was performed with duplicated and calculated for the inhibition percentages of samples by proper expression.

\section{Conclusions}

The data of this study demonstrated that the $\mathrm{MeOH}$ extract of the aerial parts of L. corniculatus subsp. corniculatus showed a remarkable in vivo antidepressant effect and the flavonoids isolated from the active subfractions could be responsible from the activity. Further studies are planned to undertaken to determine what is the mechanism of these compounds to develop new antidepressant-acting drugs.

Author Contributions: F.T.G.D.; in vivo, in vitro and isolation studies, H.K.; structure elucidation, E.S.-S.; Analyzed the data and writing manuscript, E.K.A.; in vivo studies, study design and writing manuscript. All authors have read and agreed to the published version of the manuscript.

Funding: This study was supported by the Scientific Research Project of Gazi University, Grant No: 02/2018-04.

Conflicts of Interest: The authors declare no conflict of interest.

\section{References}

1. Yemez:, B.; Alptekin, K. Depresyon etiyolojisi. Psikiyatri Dünyası 1998, 1, 21-25.

2. Ohayon, M.M. Specific characteristics of the pain/depression association in the general population. J. Clin. Psychiatr. 2004, 65, 5-9.

3. Zuckerman, B.; Amaro, H.; Bauchner, H.; Cabral, H. Depressive symptoms during pregnancy-Relationship to poor health behaviors. Am. J. Obstet. Gynecol. 1989, 160, 1107-1111. [CrossRef]

4. Cassano, P.; Fava, M. Depression and public health: An overview. J. Psychosom. Res. 2002, 53, $849-857$. [CrossRef]

5. (WHO), W.H.O. Depression: Key Facts. Available online: http://www.who.int/en/news-room/fact-sheets/ detail/depression (accessed on 13 February 2020).

6. Hadizadeh, F.; Ebrahimzadeh, M.A.; Hosseinzadeh, H.; Motamed-Shariaty, V.; Salami, S.; Bekhradnia, A.R. Antidepressant and antioxidant activities of some 2-benzoxazolinone derivatives as bupropion analogues. Pharmacologyonline 2009, 1, 331-335.

7. Bet, P.M.; Hugtenburg, J.G.; Penninx, B.W.J.H.; Hoogendijk, W.J.G. Side effects of antidepressants during long-term use in a naturalistic setting. Eur. Neuropsychopharmacol. 2013, 23, 1443-1451. [CrossRef]

8. Zhang, Z.J. Therapeutic effects of herbal extracts and constituents in animal models of psychiatric disorders. Life Sci. 2004, 75, 1659-1699. [CrossRef]

9. Altundag, E.; Ozturk, M. Ethnomedicinal studies on the plant resources of east Anatolia, Turkey. Procd. Soc. Behv. 2011, 19, 756-777. [CrossRef] 
10. Rates, S.M.K. Plants as source of drugs. Toxicon 2001, 39, 603-613. [CrossRef]

11. Mezrag, A.; Mohamed, B.; Nicola, M.; Massimiliano, D.; Aissaoui, M.; Lorella, S. Phytochemical investigation and citotoxix activity of Lotus corniculatus. Pharmacology Online 2014, 3, 222-225.

12. Harborne, J.B. Gossypetin and herbacetin as taxonomic markers in higher plants. Phytochemistry 1969, 8, 177-183. [CrossRef]

13. Reynaud, J.; Jay, M.; Raynaud, J. Flavonoid glycosides of Lotus corniculatus (Leguminosae). Phytochemistry 1982, 21, 2604-2605. [CrossRef]

14. Walewska, E.; Strzelecka, H. Flavonoid compounds in aerial parts of Lotus corniculatus L. Herba Polonica 1984, 30, 151-157.

15. Khalighi-Sigaroodi, F.; Ahvazi, M.; Hadjiakhoondi, A.; Taghizadeh, M.; Yazdani, D.; Khalighi-Sigaroodi, S.; Bidel, S. Cytotoxicity and antioxidant activity of 23 plant species of Leguminosae family. Iran J. Pharm. Res. 2012, 11, 295-302.

16. Guan, L.P.; Liu, B.Y. Antidepressant-like effects and mechanisms of flavonoids and related analogues. Eur. J. Med. Chem. 2016, 121, 47-57. [CrossRef]

17. Chilpa, R.R.; Estrada, M.J. Chemistry of antidotal plants. Interciencia 1995, 20, 257+.

18. Maurich, T.; Iorio, M.; Chimenti, D.; Turchi, G. Erybraedin C and bitucarpin A, two structurally related pterocarpans purified from Bituminaria bituminosa, induced apoptosis in human colon adenocarcinoma cell lines MMR- and p53-proficient and -deficient in a dose-, time-, and structure-dependent fashion. Chem.-Biol. Interact. 2006, 159, 104-116. [CrossRef]

19. Gnanamanickam, S.S.; Smith, D.A. Selective toxicity of isoflavonoid phytoalexins to gram-positive bacteria. Phytopathology 1980, 70, 894-896. [CrossRef]

20. Soby, S.; Caldera, S.; Bates, R.; VanEtten, H. Detoxification of the phytoalexins maackiain and medicarpin by fungal pathogens of alfalfa. Phytochemistry 1996, 41, 759-765. [CrossRef]

21. Messina, M.; Gleason, C. Evaluation of the potential antidepressant effects of soybean isoflavones. Menopause-J. N. Am. Menopause Soc. 2016, 23, 1348-1360. [CrossRef]

22. Mohan, M.; Attarde, D.; Momin, R.; Kasture, S. Antidepressant, anxiolytic and adaptogenic activity of torvanol A: An isoflavonoid from seeds of Solanum torvum. Nat. Prod. Res. 2013, 27, 2140-2143. [CrossRef] [PubMed]

23. Lin, H.H. In vitro and in vivo atheroprotective effects of gossypetin against endothelial cell injury by induction of autophagy. Chem. Res. Toxicol. 2015, 28, 202-215. [CrossRef] [PubMed]

24. Khan, A.; Manna, K.; Bose, C.; Sinha, M.; Das, D.K.; Kesh, S.B.; Chakrabarty, A.; Banerji, A.; Dey, S. Gossypetin, a naturally occurring hexahydroxy flavone, ameliorates gamma radiation-mediated DNA damage. Int. J. Radiat. Biol. 2013, 89, 965-975. [CrossRef] [PubMed]

25. Mounnissamy, V.M.; Gunasegaran, R.; Gopal, V.; Saraswathy, A. Diuretic activity of gossypetin isolated from Hibiscus sabdariffa in rats. Hamdard Med. 2002, 45, 68-70.

26. Gulsheen Kumar, A.; Sharma, A. Antianxiety and antidepressant activity guided isolation and characterization of gossypetin from Hibiscus sabdariffa Linn. calyces. J. Biol. Act. Prod. Nat. 2019, 9, 205-214. [CrossRef]

27. Cai, H.D.; Tao, W.W.; Su, S.L.; Guo, S.; Zhu, Y.; Guo, J.M.; Duan, J.A. Antidepressant activity of flavonoid ethanol extract of Abelmoschus manihot corolla with BDNF up-regulation in the hippocampus. Yao xue xue bao = Acta pharmaceutica Sinica 2017, 52, 222-228.

28. Kim, J.H.; Lee, J.K. Naringenin enhances NK cell lysis activity by increasing the expression of NKG2D ligands on Burkitt's lymphoma cells. Arch. Pharmacal Res. 2015, 38, 2042-2048. [CrossRef]

29. Al-Rejaie, S.S.; Abuohashish, H.M.; Al-Enazi, M.M.; Al-Assaf, A.H.; Parmar, M.Y.; Ahmed, M.M. Protective effect of naringenin on acetic acid-induced ulcerative colitis in rats. World J. Gastroenterol. 2013, 19, 5633-5644. [CrossRef]

30. Park, J.H.; Lee, J.W.; Paik, H.D.; Cho, S.G.; Nah, S.Y.; Park, Y.S.; Han, Y.S. Cytotoxic effects of 7-O-Butyl naringenin on human breast cancer MCF-7 cells. Food Sci. Biotechnol. 2010, 19, 717-724. [CrossRef]

31. Patel, K.; Singh, G.K.; Patel, D.K. A review on pharmacological and analytical aspects of naringenin. Chin. J. Integr. Med. 2018, 24, 551-560. [CrossRef]

32. Yi, L.T.; Li, C.F.; Zhan, X.; Cui, C.C.; Xiao, F.; Zhou, L.P.; Xie, Y. Involvement of monoaminergic system in the antidepressant-like effect of the flavonoid naringenin in mice. Prog. Neuropsychopharmacol. Biol. Psychiatry 2010, 34, 1223-1228. [CrossRef] 
33. Yi, L.T.; Li, J.; Li, H.C.; Su, D.X.; Quan, X.B.; He, X.C.; Wang, X.H. Antidepressant-like behavioral, neurochemical and neuroendocrine effects of naringenin in the mouse repeated tail suspension test. Prog. Neuropsychopharmacol. Biol. Psychiatry 2012, 39, 175-181. [CrossRef] [PubMed]

34. Tamminga, C.A.; Nemeroff, C.B.; Blakely, R.D.; Brady, L.; Carter, C.S.; Davis, K.L.; Dingledine, R.; Gorman, J.M.; Grigoriadis, D.E.; Henderson, D.C.; et al. Developing novel treatments for mood disorders: Accelerating discovery. Biol. Psychiatry 2002, 52, 589-609. [CrossRef]

35. Sakagami, Y.; Kumai, S.; Suzuki, A. Isolation and structure of medicarpin- $\beta$-D-glucoside in alfalfa. Agric. Biol. Chem. 1974, 38, 1031-1034. [CrossRef]

36. Yaque, J.G.; Cuéllar, A.; Gaysinski, M.; Monan, M.; Nossin, E.; François-Haugrin, F. New reported flavonol characterized by NMR from the petals of Talipariti elatum S. w. in Cuba. Am. J. Plant Sci. 2016, 7, 1564-1569. [CrossRef]

37. Ehab, A.R.; Mohammed, H.; Hazem, A.K.; Hassan, A.A. Flavanone glycosides from Gleditsia caspia. J. Nat. Prod. 2010, 3, 35-46.

38. Porsolt, R.D.; Le Pichon, M.; Jalfre, M. Depression: A new animal model sensitive to antidepressant treatments. Nature 1977, 266, 730-732. [CrossRef]

39. Dereli Gürağaç, F.T.; Ilhan, M.; Akkol, E.K. Discovery of new antidepressant agents: In vivo study on Anthemis wiedemanniana Fisch \& Mey. J. Ethnopharmacol. 2018, 226, 11-16.

40. Steru, L.; Chermat, R.; Thierry, B.; Simon, P. The tail suspension test-A new method for screening antidepressants in mice. Psychopharmacology 1985, 85, 367-370. [CrossRef]

41. Gürağaç Dereli, F.T.; Ilhan, M.; Küpeli Akkol, E.J.E. Identification of the main active antidepressant constituents in a traditional Turkish medicinal plant, Centaurea kurdica Reichardt. J. Ethnopharmacol. 2020, 112373. [CrossRef]

42. Alpermann, H.G.; Schacht, U.; Usinger, P.; Hock, F.J. Pharmacological effects of Hoe-249-A new potential antidepressant. Drug Dev. Res. 1992, 25, 267-282. [CrossRef] 
43. Hwang, K.H. Monoamine oxidase inhibitory activities of Korean medicinal plants classified to cold drugs by the theory of KIMI. Food Sci. Biotechnol. 2003, 12, 238-241.

44. Küpeli Akkol, E.; Gürağaç, F.T.; Ilhan, M. Plant-based therapies for depressive disorders: Evaluating antidepressant activity of Micromeria myrtifolia Boiss. \& Hohen. Molecules 2019, 24, 1-13.

Sample Availability: Samples of the compounds are available from the authors.

(C) 2020 by the authors. Licensee MDPI, Basel, Switzerland. This article is an open access article distributed under the terms and conditions of the Creative Commons Attribution (CC BY) license (http://creativecommons.org/licenses/by/4.0/). 